\title{
Comportamento mecânico dos grãos de feijão submetidos a compressão
}

\author{
$\overline{\text { Osvaldo Resende }^{1} \text {, Paulo C. Corrêa }{ }^{2} \text {, Deise M. Ribeiro }{ }^{1} \text { \& Acácio Figueiredo Neto }}{ }^{1}$
}

\begin{abstract}
RESUMO
Verificar a influência do teor de água nos valores da força máxima de compressão para deformações fixas e determinar o módulo proporcional de deformidade de grãos de feijão submetidos a compressão em três diferentes posições, foram os principais objetivos que estimularam o presente trabalho. Para isto, utilizaram-se grãos de feijão com teores de água variando de 0,13 a 0,45 (b.s.) comprimidos uniaxicialmente, entre duas placas paralelas, na direção de suas três dimensões essenciais. A partir dos resultados obtidos, conclui-se que a força de compressão necessária para deformar o feijão diminui com o aumento do teor de água, sendo maior para a direção perpendicular à divisão dos cotilédones (posição natural de repouso). O módulo proporcional de deformidade aumenta com a redução do teor de água e da deformação do produto, obtendo-se valores para a faixa de umidade estudada, entre $1,7 \times 10^{7}$ a $71,3 \times 10^{7} \mathrm{~Pa}$, dependendo da posição do grão.
\end{abstract}

Palavras-chave: propriedades reológicas, módulo proporcional de deformidade, teor de água

\section{Mechanical behavior of bean grains under compression}

\begin{abstract}
This work aims to determine the effect of soybean grain moisture content upon the maximum compression force values for fixed deformations and to determine the proportional deformity modulus under different compression positions. Edible beans with 0.45 to 0.13 (d.b.) moisture content were compressed uniaxialy between two parallel plates towards their three main axes. From the results it was concluded that the compression force decreased with moisture content increase, and the highest value corresponded to the direction perpendicular to cotyledon division (repose position). The proportional deformity modulus increases with the reduction of moisture content and with the deformation of the product, presenting values, for the studied moisture content, between $1.7 \times 10^{7}$ to $71.3 \times 10^{7} \mathrm{~Pa}$, depending on grain position.
\end{abstract}

Key words: rheological properties, proportional deformity modulus, moisture content

Doutorandos em Engenharia Agrícola/UFV, Av. P. H Rolfs s/n - CENTREINAR - Campus UFV, CEP 36570-000, Viçosa, MG. Fone: (31) $3899-2030$. E-mail: osvresende@yahoo.com.br; deise_eng@yahoo.com.br; acaciofneto@yahoo.com.br

2 DEA/UFV. Fone: (31) 3899-2118. E-mail: copace@ufv.br 


\section{INTRODUÇÃO}

O estudo das características mecânicas dos produtos agrícolas é imprescindível para que os equipamentos possam ser desenvolvidos com vistas a atingir a máxima eficiência sem, contudo, comprometer a qualidade final do produto. As trincas e quebras ocorrem nos grãos se os esforços, aos quais são submetidos, excedem a força de resistência do material (Liu et al., 1990).

Durante a colheita, manuseio, transporte e armazenamento, os grãos são submetidos a uma série de pressões estáticas de várias magnitudes e dinâmicas, como impacto de alta velocidade, causando escoriações, esmagamento e trincas, aumentando a sua suscetibilidade a deterioração, durante o armazenamento (Bargale-Praveen et al., 1995).

Dentre as diversas propriedades mecânicas o módulo de deformidade permite que se realizem comparações de resistência relativa entre os diversos materiais. Para determinação do módulo de deformidade do produto, faz-se a separação da sua deformação total nas duas componentes: elástica e plástica; assim, com a obtenção de curvas de força em função da deformação durante a aplicação de cargas ao produto e se considerando a sua deformação total, obter-se-á o módulo de deformidade total do produto. Segundo Couto et al. (2002), no estudo do comportamento mecânico de um material o módulo de deformidade é considerado mais significativo que o de elasticidade, visto que, quando um produto é comprimido, a deformação total é que tem aplicação prática.

O módulo de deformidade é função da razão de Poisson, que assume valores constantes para cada material, sendo seu valor desconhecido para o feijão. Na ausência deste valor, Batista et al. (2003) utilizaram outra variável proporcional ao módulo de deformidade, denominada módulo proporcional de deformidade.

Diversos fatores afetam as propriedades mecânicas dos produtos agrícolas destacando-se, entre eles, a temperatura de secagem, o teor de água, o tipo de força e a região do grão, na qual este tipo de força é aplicado (Mohsenin, 1986; Prussia \& Campbell, 1985; Li et al., 1989; Zhang et al., 1989).

Na determinação do módulo proporcional de deformidade dos frutos de café nos estádios de maturação verde, verdoengo e cereja, com diferentes teores de água, Couto et al. (2002) concluíram que o módulo proporcional de deformidade diminui com o aumento da deformação do fruto.

Vários pesquisadores afirmam que a temperatura do ar de secagem é um dos fatores que mais afetam as propriedades mecânicas de grãos agrícolas (Gustafson \& Hall, 1972; White et al., 1982).

Batista et al. (2003), verificaram que o módulo proporcional de deformidade de frutos de café, para a faixa de umidade de 0,14 a 1,50 (b.s.), nos três estádios de maturação, submetidos às temperaturas de secagem (40, 50 e $\left.60^{\circ} \mathrm{C}\right)$, reduziu com o aumento das deformações do produto, condições em que o módulo proporcional de deformidade apresentou valores entre $2,0 \times 10^{7}$ a $18,0 \times 10^{7} \mathrm{~Pa}$ para os frutos de café cereja, 5,0 x $10^{7}$ a 40,0 x $10^{7} \mathrm{~Pa}$ para os frutos verdes e $1,0 \times 10^{7}$ a $50 \times 10^{7} \mathrm{~Pa}$ para os frutos verdoengos.

Liu et al. (1990) constataram, por meio de teste de com- pressão em soja, efeitos significativos do teor de água e da temperatura do ar de secagem no comportamento mecânico do produto. Com a redução da temperatura do ar de secagem, as forças para a ruptura do grão aumentaram e, com a elevação do teor de água do produto, essas forças diminuíram.

Gupta \& Das (2000), avaliando o comportamento mecânico das sementes de girassol notaram que, com o aumento do teor de água do produto de 3,8 para $16,6 \%$ b.u., a força para a ruptura do produto foi reduzida e sua deformação aumentou.

Henry et al. (2000) estudando a resistência da soja a compressão em três orientações e para quatro teores de água observaram que, ao comprimir o grão, a força de ruptura perpendicular à divisão dos cotilédones foi maior que para as outras orientações mas apresentou menor deformação e, também, que a resistência a compressão diminuiu com o aumento do teor de água.

Oliveros-Tascón et al. (2002) avaliaram a influência do ataque da broca-do-café na firmeza dos frutos de café cereja e pergaminho (seco e úmido) submetidos aos testes de compressão. Para os frutos cereja não houve diferença significativa entre a firmeza dos frutos sadios e brocados; já para o café em pergaminho, a firmeza dos grãos sadios foi estatisticamente superior àquela dos grãos brocados, evidenciando a influência do ataque dos insetos nas propriedades mecânicas dos frutos de café.

Considerando-se o exposto e a escassez de informações teóricas em literatura especializada sobre as propriedades mecânicas do feijão objetivou-se, através do presente trabalho, verificar a influência do teor de água nos valores da força máxima de compressão para deformações fixas e determinar o módulo proporcional de deformidade de grãos de feijão submetidos a compressão, em diferentes posições.

\section{MATERIAL E MÉTODOS}

O presente trabalho foi desenvolvido no Laboratório de Propriedades Físicas e Qualidade de Produtos Agrícolas pertencente ao Centro Nacional de Treinamento em Armazenagem (CENTREINAR) da Universidade Federal de Viçosa UFV, Viçosa, MG.

Para condução do experimento utilizaram-se grãos de feijão (Phaseolus vulgaris L.) do grupo vermelho, cultivar vulgarmente denominado "vermelhinho", cultivados na safra de inverno do ano de 2003 no município de Cajuri, MG, e colhidos manualmente com teor de água de aproximadamente 0,45 (b.s.).

Os diversos teores de água foram obtidos pela secagem realizada em estufa com ventilação forçada, mantida a uma temperatura de $40{ }^{\circ} \mathrm{C}$ e umidade relativa de $25 \%$. A redução do teor de água ao longo da secagem, se fez acompanhar do método gravimétrico (perda de massa), conhecendo-se o nível de umidade inicial do produto, até atingir o teor de água final de 0,13 (b.s.), com auxílio de uma balança semi-analítica com precisão de $0,01 \mathrm{~g}$.

O teor de água do produto foi determinado pelo método de estufa, a $105 \pm 1{ }^{\circ} \mathrm{C}$, até massa constante. Para cada teor 
de água obtido, as amostras foram homogeneizadas e encaminhadas para determinação das propriedades mecânicas, a temperatura controlada de $22 \pm 2{ }^{\circ} \mathrm{C}$.

Os ensaios experimentais de compressão nos grãos, testados individualmente, foram realizados em uma máquina de ensaio universal de teste modelo "TA Hdi Texture Analyser”, utilizando-se uma célula de carga de $500 \mathrm{~N}$.

Os grãos foram submetidos a compressão uniaxial, entre duas placas paralelas, aplicada em suas três dimensões principais: espessura $\left(\mathrm{P}_{1}\right)$, largura $\left(\mathrm{P}_{2}\right)$ e comprimento $\left(\mathrm{P}_{3}\right)$ indicadas na Figura 1, a uma taxa de aplicação de força de $0,001 \mathrm{~m} \mathrm{~s}^{-1}$. Para cada uma das posições foram utilizados dez grãos de feijão. $\mathrm{O}$ ensaio de compressão foi finalizado quando a deformação atingiu $0,002 \mathrm{~m}$.

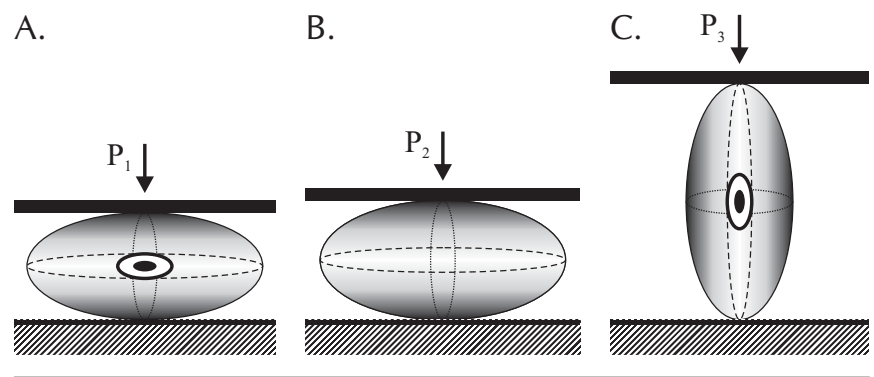

Figura 1. Orientações dos grãos de feijão durante os ensaios de compressão, (A) menor eixo, espessura; (B) eixo médio, largura; (C) maior eixo, comprimento

O módulo proporcional de deformidade do feijão $\left(\mathrm{E}_{\mathrm{p}}\right)$ foi determinado para as deformações de 0,$4 ; 0,8 ; 1,2 ; 1,6$ e $2,0 \times 10^{-3} \mathrm{~m}$, adaptadas das deformações utilizadas por Вatista et al. (2003), de acordo com a seguinte expressão:

$$
\mathrm{Ep}=\frac{\mathrm{E}}{\left(1-\mu^{2}\right)}=\frac{0,531 \cdot \mathrm{F}}{\mathrm{D}^{3 / 2}} \cdot\left[2 \cdot\left(\frac{1}{\mathrm{r}}+\frac{1}{\mathrm{R}}\right)^{1 / 3}\right]^{3 / 2}
$$

em que:

$$
\begin{aligned}
& \text { Ep - } \text { módulo proporcional de deformidade, Pa } \\
& \text { E - módulo de deformidade, } \mathrm{Pa} \\
& \mathrm{F} \text { - } \text { força, } \mathrm{N} \\
& \mathrm{D} \text { - } \text { deformação total (elástica e plástica) do corpo } \\
& \text { nos pontos de contato com a placa superior e } \\
& \text { inferior, } \mathrm{m} \\
& \mu \text { - razão de Poisson } \\
& \mathrm{R}, \mathrm{r} \text { - } \text { raios de curvatura no ponto de contato, } \mathrm{m}
\end{aligned}
$$

Obtiveram-se os valores dos raios de curvatura (r e R) dos grãos nos pontos de contato, para cada posição e teor de água, através de ajustes de circunferência às curvaturas do corpo, segundo os planos coordenados de cada posição de compressão, conforme ilustrado na Figura 2.

Os dados da força máxima de compressão e do módulo proporcional de deformidade do feijão foram representados em função do teor de água e da posição de compressão dos grãos.

$\mathrm{O}$ experimento foi montado segundo o esquema fatorial 7 x 5 x 3 (7 teores de água, 5 deformações e 3 posições de compressão), no delineamento inteiramente casualizado com dez repetições. Os dados foram analisados por meio de análise de variância e regressão e os modelos selecionados, baseando-se
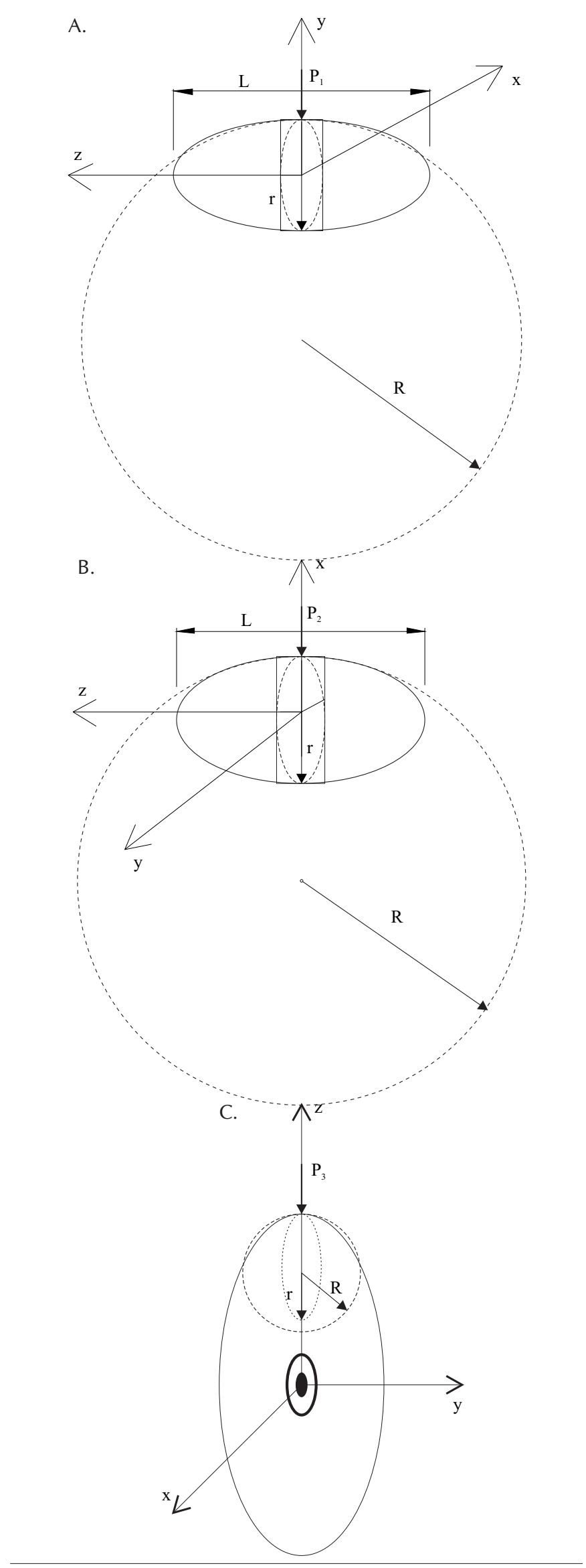

Figura 2. Raios de curvatura do grão de feijão na região de contato entre o produto e a placa de compressão, $(\mathrm{A})$ compressão na posição $\mathrm{P}_{1}$; $(\mathrm{B})$ compressão na posição $\mathrm{P}_{2} ;(\mathrm{C})$ compressão na posição $\mathrm{P}_{3}$ 
na significância dos coeficientes de regressão, utilizando-se o teste de "t" e se adotando o nível de 5\% de probabilidade com auxílio do programa computacional Sigma Plot 7.0, na magnitude do coeficiente de determinação e do erro médio relativo (P) e, ainda, no conhecimento da evolução do fenômeno biológico. O erro médio relativo para cada um dos modelos foi calculado conforme a seguinte expressão:

$$
\mathrm{P}=\frac{100}{\mathrm{n}} \sum_{\mathrm{i}=1}^{\mathrm{n}} \frac{|\mathrm{Y}-\hat{\mathrm{Y}}|}{\mathrm{Y}}
$$

em que:

$$
\begin{aligned}
& \text { P - erro médio relativo, \% } \\
& \text { Y - valor observado experimentalmente } \\
& \hat{Y} \text { - valor calculado pelo modelo } \\
& \text { n - número de observações experimentais }
\end{aligned}
$$

\section{RESULTADOS E DISCUSSÃO}

Os valores médios dos raios de curvatura dos grãos de feijão para cada posição e teor de água, utilizados nos cálculos para determinação do módulo proporcional de deformidade, estão na Tabela 1, através da qual se verifica que os raios de curvatura oscilaram com o teor de água do produto; entretanto, sem ocorrência de tendência clara em função desta variável. Os raios de curvatura indicaram valores distintos para cada posição de compressão do grão decrescendo de acordo

\begin{tabular}{|c|c|c|c|c|c|c|}
\hline \multirow{3}{*}{$\begin{array}{c}\text { Teor de } \\
\text { água (b.s.) }\end{array}$} & \multicolumn{6}{|c|}{ Posição } \\
\hline & \multicolumn{2}{|c|}{$P_{1}$} & \multicolumn{2}{|c|}{$P_{2}$} & \multicolumn{2}{|c|}{$P_{3}$} \\
\hline & $r$ & R & $r$ & R & $r$ & $\mathbf{R}$ \\
\hline 0,423 & 4,39 & 8,49 & 1,99 & 7,44 & 1,39 & 2,45 \\
\hline 0,370 & 4,50 & 8,64 & 1,97 & 7,33 & 1,29 & 2,51 \\
\hline 0,311 & 4,31 & 8,51 & 1,93 & 7,37 & 1,29 & 2,55 \\
\hline 0,258 & 4,43 & 9,28 & 1,98 & 7,69 & 1,26 & 2,49 \\
\hline 0,208 & 4,05 & 8,78 & 1,98 & 7,73 & 1,37 & 2,52 \\
\hline 0,166 & 4,07 & 9,05 & 2,02 & 7,18 & 1,38 & 2,46 \\
\hline 0,136 & 4,04 & 8,58 & 2,15 & 7,39 & 1,43 & 2,43 \\
\hline
\end{tabular}
com a seqüência: posição de repouso, força aplicada sobre o hilo e força aplicada com o hilo na posição vertical.

Tabela 1. Valores médios dos raios de curvatura dos grãos de feijão (x $\left.10^{-3} \mathrm{~m}\right)$ para cada posição e teor de água (b.s.)

Encontram-se, na Figura 3, os valores médios da força máxima de compressão nas três posições de compressão $\left(\mathrm{P}_{1}, \mathrm{P}_{2}\right.$ e $\left.\mathrm{P}_{3}\right)$, em função do teor de água (b.s.) para as diversas deformações.

Analisando-se a Figura 3, vê-se que a força de compressão necessária para deformar o feijão diminuiu com o aumento do teor de água, para as três posições de compressão; resultados semelhantes foram observados por Henry et al. (2000) e Ribeiro et al. (2005) para grãos de soja em diferentes teores de água. A força média necessária para as diversas deformações em função do teor de água variou entre 22,3 e 551,7 N; 10,5 e 253,1 N e 11,6 e $143 \mathrm{~N}$, para as posições $\mathrm{P}_{1}, \mathrm{P}_{2}$ e $\mathrm{P}_{3}$, respectivamente; os grãos com teor de água mais elevados oferecem menor resistência a compressão, aumentando proporcionalmente com a
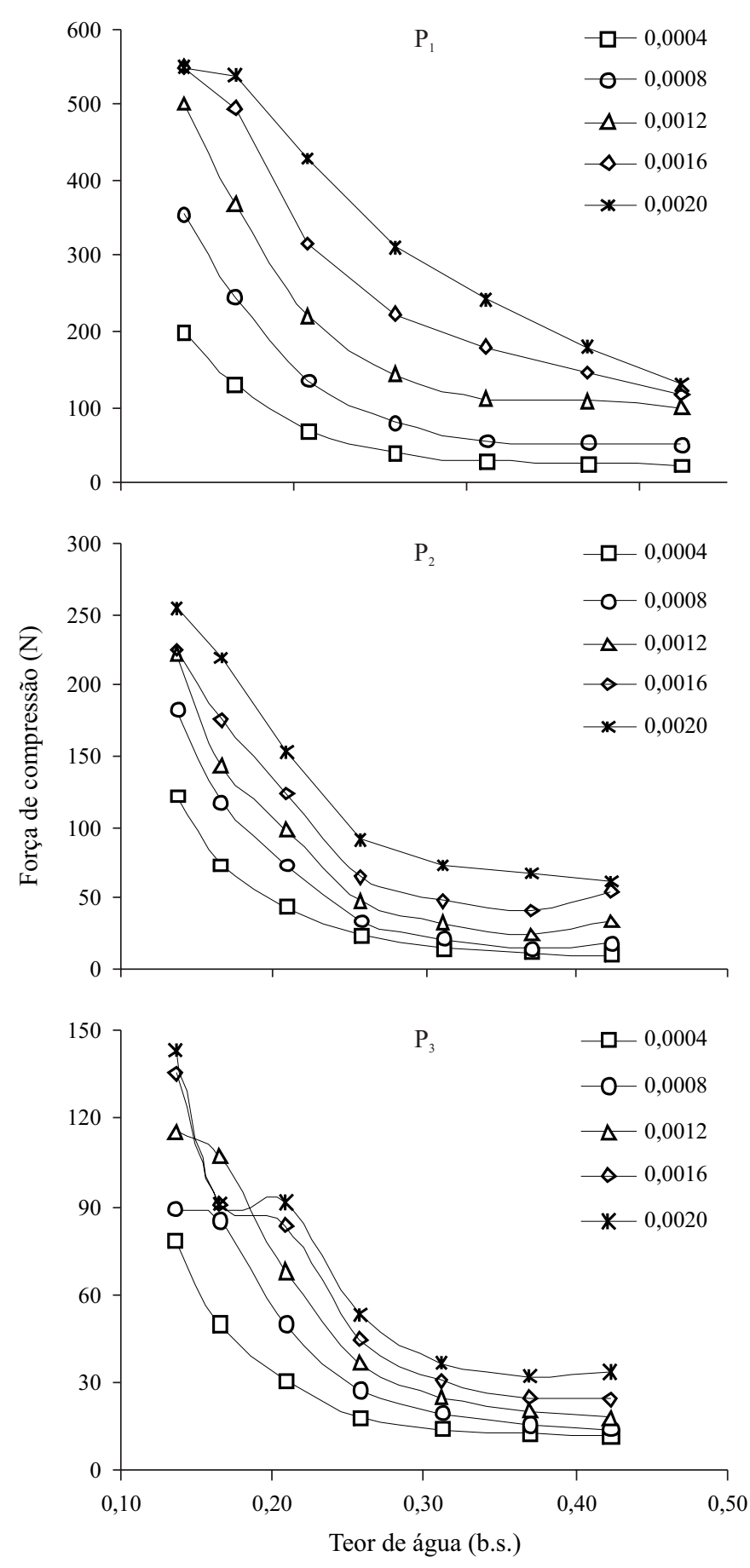

Figura 3. Valores médios da força máxima de compressão $(\mathrm{N})$ nas três posições de compressão $\left(\mathrm{P}_{1}, \mathrm{P}_{2}\right.$ e $\left.\mathrm{P}_{3}\right)$, em função do teor de água (b.s.) para as deformações de 0,$0004 ; 0,0008 ; 0,0012 ; 0,0016$ e 0,002 m

redução da umidade; esta tendência se deve, provavelmente, a uma mudança gradual na integridade da matriz celular com a redução do teor de água (Gupta \& Das, 2000).

Como previsto, com o aumento da deformação do produto obteve-se uma sensível elevação da força, independente da posição de compressão dos grãos.

Observam-se, ainda, diferenças entre as três posições de compressão (espessura, largura e comprimento) dos grãos, sendo os maiores valores da força de compressão notados para a posição $\mathrm{P}_{1}$ (perpendicular à divisão dos cotilédones), de maneira semelhante aos resultados observados por Henry 
et al. (2000). Este fato é devido, sem dúvida, ao surgimento de tensões cisalhantes nos tecidos internos que, dependendo da direção do esforço aplicado, requer uma força diferenciada para deformar o grão. As deformações causam ruptura dos cotilédones que apresentavam, de início, um arranjamento celular definido (Peterson et al., 1995).

A partir dos dados de força de compressão obtiveram-se os módulos proporcionais de deformidade, os quais apresentaram o mesmo comportamento da força de compressão, em função do teor de água.

Apresenta-se, na Tabela 2, o resumo da análise de variância para o módulo proporcional de deformidade do feijão, obtido nas diversas condições experimentais e se verifica que, para os testes empregados, há diferenças significativas para os fatores analisados assim como para as interações entre os teores de água, as deformações e as posições de compressão.

A Tabela 3 apresenta as equações de regressão ajustadas aos

Tabela 2. Resumo da análise de variância do módulo proporcional de deformidade do feijão obtido para diversos teores de água $(0,42 ; 0,37$; 0,$31 ; 0,26 ; 0,21 ; 0,17 ; 0,13$ b.s.), deformações $(0,0004 ; 0,0008 ; 0,0012$; $0,0016$ e $0,002 \mathrm{~m})$ e posições de compressão $\left(\mathrm{P}_{1}, \mathrm{P}_{2}\right.$ e $\left.\mathrm{P}_{3}\right)$

\begin{tabular}{lrr}
\hline Fonte de Variação & G.L. & Quadrado médio \\
Teor de água $(\mathrm{U})$ & 6 & $12983,9143^{* *}$ \\
Deformação $(\mathrm{D})$ & 4 & $7638,7886^{\star *}$ \\
Posição (P) & 2 & $5763,1271^{\star *}$ \\
U x D & 24 & $1288,2175^{\star *}$ \\
U X P & 12 & $519,4171^{* *}$ \\
D x P & 8 & $13,5819^{*}$ \\
U x D X P & 48 & $31,5196^{* *}$ \\
Resíduo & 945 & \\
Total & 1049 & \\
CV $(\%)=21,59$ & & \\
\hline
\end{tabular}

* Significativo a $5 \%$ pelo teste $\mathrm{F}$; ${ }^{* \star}$ Significativo a $1 \%$ pelo teste $\mathrm{F}$

valores experimentais do módulo proporcional de deformidade do feijão, em função do teor de água e da deformação, para cada posição de compressão. Pela análise dos resultados, vêse que as equações ajustadas se mostraram satisfatórias, apresentando altos valores do coeficiente de determinação $\left(R^{2}\right)$ e reduzidas magnitudes do erro médio percentual (P).

Tabela 3. Modelos ajustados aos valores experimentais do módulo proporcional de deformidade do feijão (Ep) em função do teor de água (U) e da deformação (D), para cada posição de compressão

\begin{tabular}{|c|c|c|c|}
\hline Posição & Modelo & $\mathbf{R}^{2}(\%)$ & $P(\%)$ \\
\hline$P_{1}$ & $\begin{array}{l}\mathrm{Ep}=1,32 \cdot 10^{9}-5,68 \cdot 10^{9} \cdot \mathrm{U}+4,57 \cdot 10^{11} \cdot \mathrm{D}+ \\
6,63 \cdot 10^{9} \cdot \mathrm{U}^{2}+6,63 \cdot 10^{13} \cdot \mathrm{D}^{2}-7,96 \cdot 10^{11} \cdot \mathrm{U} \cdot \mathrm{D}\end{array}$ & $96,9^{*}$ & 28,7 \\
\hline$P_{2}$ & $\begin{array}{l}\mathrm{Ep}=1,05 \cdot 10^{9}-4,17 \cdot 10^{9} \cdot \mathrm{U}-5,07 \cdot 10^{11} \cdot \mathrm{D}+ \\
4,40 \cdot 10^{9} \cdot \mathrm{U}^{2}+8,29 \cdot 10^{13} \cdot \mathrm{D}^{2}+8,34 \cdot 10^{11} \cdot \mathrm{U} \cdot \mathrm{D}\end{array}$ & $95,6^{*}$ & 31,8 \\
\hline$P_{3}$ & $\begin{array}{l}\mathrm{Ep}=8,53 \cdot 10^{8}-3,11 \cdot 10^{9} \cdot \mathrm{U}-4,50 \cdot 10^{11} \cdot \mathrm{D}+ \\
3,28 \cdot 10^{9} \cdot \mathrm{U}^{2}+8,36 \cdot 10^{13} \cdot \mathrm{D}^{2}+6,01 \cdot 10^{11} \cdot \mathrm{U} \cdot \mathrm{D}\end{array}$ & $95,3^{*}$ & 31,7 \\
\hline
\end{tabular}

em que:

$$
\begin{aligned}
& \text { Ep - módulo proporcional de deformidade, Pa } \\
& \text { U - teor de água, b.s. } \\
& \text { D - deformação, m }
\end{aligned}
$$

Tem-se, na Figura 4, as superfícies de resposta ajustada, de acordo com as equações anteriores, para o módulo proporcional
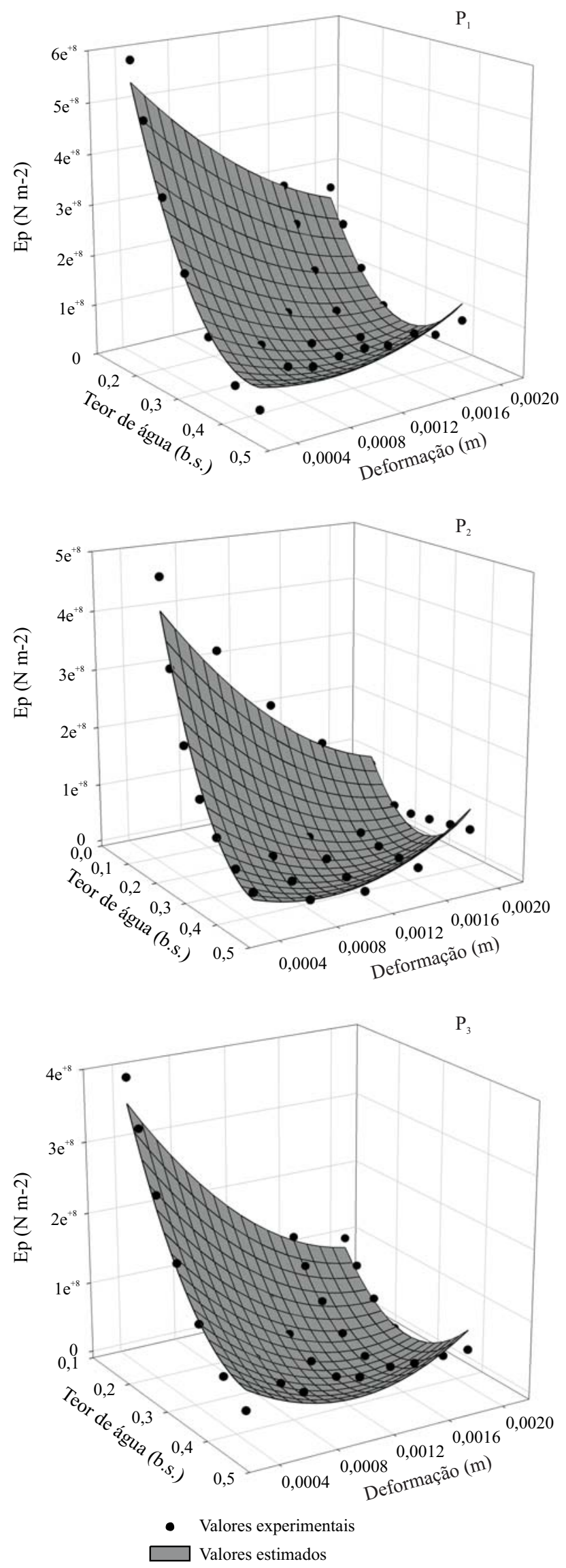

Figura 4. Valores médios do módulo proporcional de deformidade do feijão (x $\left.10^{7} \mathrm{~Pa}\right)$ nas três posições de compressão $\left(\mathrm{P}_{1}, \mathrm{P}_{2}\right.$ e $\left.\mathrm{P}_{3}\right)$, em função do teor de água (b.s.) e deformações 
de deformidade do feijão, em função do teor de água e da deformação, para cada posição de compressão. O valor elevado do módulo de deformidade significa que uma força maior deve ser aplicada ao produto para, então, se obter determinada deformação (Batista et al., 2003). Observa-se que, independente da posição de compressão, os valores do módulo proporcional de deformidade aumentam com a redução do teor de água. Esses resultados corroboram os observados por Ribeiro et al. (2005) para soja e Batista et al. (2003) para os frutos de café.

Para a faixa de umidade estudada os valores do módulo proporcional de deformidade variaram entre 4,1 a 71,3 x $10^{7} \mathrm{~Pa}$ para a posição $\mathrm{P}_{1}$; 2,6 a 56,4 x $10^{7} \mathrm{~Pa}$ para a posição $\mathrm{P}_{2}$ e 1,7 a $48,7 \times 10^{7} \mathrm{~Pa}$ para a posição $\mathrm{P}_{3}$. Referidos valores estão coerentes com os observados por Ribeiro et al. (2005) para grãos de soja, que obtiveram o módulo proporcional de deformidade de $2,31 \times 10^{7}$ a $1,07 \times 10^{8} \mathrm{~Pa}$ para $\mathrm{P}_{1} ; 1,68 \times 10^{7}$ a $5,42 \times 10^{7}$ Pa para $P_{2}$ e $1,02 \times 10^{7}$ a 5,43 x $10^{7}$ Pa para $P_{3}$, para a faixa de umidade de 0,58 a 0,10 (b.s.) e deformação do produto de 0,002 m. Couto et al. (2002) relataram que o módulo proporcional de deformidade para o café, com teor de água de aproximadamente 2,5 (b.s.), velocidade de compressão de $1,7 \times 10^{-4} \mathrm{~m} \mathrm{~s}^{-1}$ e na faixa deformação de 1 a $6 \times 10^{-4} \mathrm{~m}$, apresentaram valores entre $1,0 \times 10^{7}$ e $3,0 \times 10^{7}$ Pa para os frutos cereja e $7,0 \times 10^{7}$ a $15,0 \times 10^{7}$ Pa para os frutos verdes; já Batista et al. (2003), verificaram que o módulo proporcional de deformidade de frutos de café, para a faixa de umidade de 1,50 a 0,14 (b.s.), nos três estádios de maturação, submetidos às temperaturas de secagem $\left(40,50\right.$ e $\left.60^{\circ} \mathrm{C}\right)$, apresentou valores entre $2,0 \times 10^{7}$ a $18,0 \times 10^{7} \mathrm{~Pa}$ para os frutos de café cereja, $5,0 \times 10^{7}$ a $40,0 \times 10^{7} \mathrm{~Pa}$ para os frutos verdes e $1,0 \times 10^{7}$ a $50 \times 10^{7} \mathrm{~Pa}$ para os frutos verdoengos.

Verifica-se, ainda, na Figura 4, que para as três posições de compressão o módulo proporcional de deformidade aumenta com a redução da deformação do produto. Resultados semelhantes foram observados por Couto et al. (2002) e Batista et al. (2003) para os frutos de café, em diferentes estádios de maturação.

\section{CONCLUSÕES}

1. A força de compressão necessária para deformar o feijão diminui com o aumento do teor de água, independentemente da posição de compressão apresentando, para as diversas deformações, valores entre 22,3 e $551,7 \mathrm{~N}$; 10,5 e 253,1 N e 11,6 e 143 N, dependendo da posição dos grãos.

2. O módulo proporcional de deformidade aumenta com a redução do teor de água e da deformação do produto, obtendose valores, para a faixa de umidade estudada, entre 4,1 a 71,3 x $10^{7} \mathrm{~Pa}$, dependendo da posição do grão a ser comprimido.

3. Os grãos de feijão apresentam maior resistência a compressão quando submetidos a esforços na posição natural de repouso.

\section{AGRADECIMENTOS}

Os autores agradecem à CAPES, ao CNPq e à FAPEMIG, pelo apoio financeiro indispensável na execução do presente trabalho.

\section{LITERATURA CITADA}

Bargale-Praveen, C.; Irudayaraj, J.; Marquist, B. Studies on rheological behaviour of canola and wheat. Journal Agricultural of Engineering Research, Silsoe, v.61, n.2, p.267-274, 1995.

Batista, C. S.; Couto, S. M.; Cecon, P. R.; Peixoto, A. B. Efeito da temperatura do ar de secagem, do teor de umidade e do estádio de maturação no módulo de deformidade de frutos de café (Coffea arabica L.). Revista Brasileira de Armazenamento, Viçosa, v. Especial café, n.6, p.42-53, 2003.

Couto, S. A.; Batista, C. S.; Peixoto, A. B.; Devilla, I. A. Comportamento mecânico de frutos de café: Módulo de deformidade. Revista Brasileira de Engenharia Agrícola e Ambiental, Campina Grande, v.6, n.2, p.285-294, 2002.

Gupta, R. K.; Das, S. K. Fracture resistance of sunflower seed and kernel to compressive loading. Journal of Food Engineering, Dublin, v.46, n.1, p.1-8, 2000.

Gustafson, R. J.; Hall, G. E. Density and porosity changes of shelled corn during drying. Transaction of the ASAE, St. Joseph, v.15, n.1, p.523-525, 1972.

Henry, Z. A.; Su, B.; Zhang, H. Resistance of soya beans to compression. Journal of Agricultural Engineering Research, Silsoe, v.76, n.2, p.175-181, 2000.

Li, Y.; Zhang, Q.; Puri, V. M.; Mambeck, H. B. Physical properties effect on stress-strain behavior of wheat en masse - Part I. Load response dependence on initial bulk density in moisture content. Transactions of the ASAE, St Joseph, v.32, n.1, p.194-202, 1989.

Liu, M.; Haghighi, K.; Stroshine, R. L.; Ting, E. C. Mechanical properties of soybean cotyledon and failure strength of soybean kernel. Transactions of the ASAE, St Joseph, v.33, n.2, p.559-565, 1990.

Mohsenin, N. N. Physical properties of plant and animal materials. New York: Gordon and Breach Publishers, 1986. 841p.

Oliveros-Tascon, C. E.; Montoya-Restrepo, E. C.; Ayala, A. A. Efecto de la broca del café em la firmeza del grano em los estados de cereja, pergamino húmedo y pergamino seco. Cenicafe, v.53, n.1, p.25-33, 2002.

Peterson, J. M.; Perdomo, J. A.; Burris, J. S. Influence of kernel position, mechanical damage and controlled deterioration estimates on hybrid maize seed quality. Seed Science and Technology, Zurich, v.23, n.1, p.647-657, 1995.

Prussia, S. E.; Campbell, D. T. Apparent modulus elasticity of maturing pecans. Transactions of the ASAE, St Joseph, v.28, n.4, p.1290-1296, 1985.

Ribeiro, D. M.; Corrêa, P. C.; Goneli, A. L. D.; Rodrigues, D. H. Propriedades mecânicas dos grãos de soja em função do teor de água. In: Congresso Brasileiro de Engenharia Agrícola, 34, 2005, Canoas, Anais... Canoas: SBEA, 2005. CD Rom.

White, G. M.; Ross, I. J.; Poneleit, C. G. Stress crack development in popcorn as influenced by drying and rehydration processes. Transactions of the ASAE, St Joseph, v.25, n.3, p.768772, 1982.

Zhang, Q.; Li, Y.; Puri, V. M.; Manbeck, H. B. Physical properties effect on stress-strain behavior of wheat en masse - Part II. Constitutive elastoplastic parameter dependence on initial bulk density and moisture content. Transactions of the ASAE. St Joseph, v.32, n.1, p.203-209, 1989. 